\title{
TU/e EmonOWEN

\section{Magnetic specific heat of the nearly-one-dimensional system tetramethyl ammonium nickel trichloride (TMNC)}

\section{Citation for published version (APA):}

Kopinga, K., De Neef, T., De Jonge, W. J. M., \& Gerstein, B. C. (1976). Magnetic specific heat of the nearly-onedimensional system tetramethyl ammonium nickel trichloride (TMNC). Physical Review B, 13(9), 3953-3955. https://doi.org/10.1103/PhysRevB.13.3953

DOI:

10.1103/PhysRevB.13.3953

Document status and date:

Published: 01/01/1976

\section{Document Version:}

Publisher's PDF, also known as Version of Record (includes final page, issue and volume numbers)

\section{Please check the document version of this publication:}

- A submitted manuscript is the version of the article upon submission and before peer-review. There can be important differences between the submitted version and the official published version of record. People interested in the research are advised to contact the author for the final version of the publication, or visit the $\mathrm{DOI}$ to the publisher's website.

- The final author version and the galley proof are versions of the publication after peer review.

- The final published version features the final layout of the paper including the volume, issue and page numbers.

Link to publication

\section{General rights}

Copyright and moral rights for the publications made accessible in the public portal are retained by the authors and/or other copyright owners and it is a condition of accessing publications that users recognise and abide by the legal requirements associated with these rights.

- Users may download and print one copy of any publication from the public portal for the purpose of private study or research.

- You may not further distribute the material or use it for any profit-making activity or commercial gain

- You may freely distribute the URL identifying the publication in the public portal.

If the publication is distributed under the terms of Article 25fa of the Dutch Copyright Act, indicated by the "Taverne" license above, please follow below link for the End User Agreement:

www.tue.nl/taverne

Take down policy

If you believe that this document breaches copyright please contact us at:

openaccess@tue.nl

providing details and we will investigate your claim. 


\title{
Magnetic specific heat of the nearly-one-dimensional system tetramethyl ammonium nickel trichloride (TMNC)
}

\author{
K. Kopinga, T. de Neef, and W. J. M. de Jonge \\ Department of Physics, Eindhoven University of Technology, Eindhoven, The Netherlands \\ B. C. Gerstein \\ Ames Laboratory, Iowa State University, Ames, Iowa 50010
}

(Received 22 December 1975)

\begin{abstract}
The specific heat of tetramethyl ammonium nickel trichloride (TMNC) for $3.5<T<20 \mathrm{~K}$ has been analyzed using the scaled lattice contribution of the isomorphic cadmium and manganese compounds and a magnetic contribution represented by the Hamiltonian $\mathcal{J C}=-2 J \Sigma_{i} \overrightarrow{\mathbf{S}}_{i} \cdot \vec{S}_{i+1}-D \Sigma_{i}\left[S_{i z}^{2}-S(S+1) / 3\right]$. The resulting parameter values $J / k=+1.7 \pm 0.3 \mathrm{~K}$, and $D / k=-3.3 \pm 0.5 \mathrm{~K}$ are qualitatively in agreement with the results from susceptibility measurements.
\end{abstract}

\section{INTRODUCTION}

Tetramethyl ammonium nickel trichloride (TMNC) can be considered as isomorphic with tetramethyl ammonium manganese trichloride (TMMC) and tetramethyl ammonium cadmium trichloride (TMCC). ${ }^{1,2}$ TMMC, especially, has been the subject of a considerable number of experimental investigations because the magnetic properties of this compound were found to display almost pure one-dimensional characteristics..$^{3-8}$ The magnetic intrachain interaction was found to be antiferromagnetic with a magnitude of about $-6.7 \mathrm{~K}$, while the ratio of the interchain and intrachain interactions $\left(J^{\prime} / J\right)$ was estimated to range between $10^{-3}$ and $10^{-5}$.

The magnetic interactions in TMNC do not seem to be very well established. The powder susceptibility has been measured for 1.6-79 $\mathrm{K}$ by Gerstein et al., ${ }^{9}$ who reported deviations from a Curie-Weiss behavior $\chi=C /(T-\theta)$ with $\theta=+4.80 \pm 5.25 \mathrm{~K}$ below $30 \mathrm{~K}$. Their data strongly suggest that the dominant interaction is ferromagnetic. Specific-heat measurements for $0.64<T<27.4 \mathrm{~K}$ performed by Hurley and Gerstein ${ }^{10}$ reveal a three-dimensional ordering peak at $T_{c} \simeq 1.21 \mathrm{~K}$ superimposed on a broad bump with a maximum of $4.5 \mathrm{~J} / \mathrm{mole} \mathrm{K}$ at $T_{m} \simeq 1.5 \mathrm{~K}$. The critical entropy amounts to $0.21 R$ $(19 \%)$, which is low compared to the values predicted for various three-dimensional $S=1$ models. ${ }^{11}$ This suggests a rather low-dimensional character of the magnetic properties, which was already conjectured from the isomorphy with TMMC. In order to account for the magnitude of the heat-capacity maximum, Hurley and Gerstein interpreted the data with the spin-1 linear Heisenberg model proposed by Weng and Griffiths, ${ }^{12}$ but this yielded an antiferromagnetic intrachain interaction, which clearly is in disagreement with powder suscepti- bility measurements.

Single-crystal susceptibility measurements in the liquid-hydrogen and helium region were performed by Dupas et al. ${ }^{13}$ They analyzed their data within the framework of a Hamiltonian describing a Heisenberg linear-chain system with uniaxial single-ion anisotropy

$$
\mathcal{H}=-2 J \sum_{i} \overrightarrow{\mathrm{S}}_{i} \cdot \overrightarrow{\mathrm{S}}_{i+1}-D \sum_{i}\left[S_{i z}^{2}-\frac{1}{3} S(S+1)\right] .
$$

This resulted in $J / k=+1.1 \mathrm{~K}$ and $D / k=-2.1 \mathrm{~K}$. The interchain interactions were estimated from $\chi_{\perp}$ in the ordered state and from a Green's-function method, ${ }^{14}$ which yielded a $J^{\prime} / J$ value of 3 $\times 10^{-2}$ and $7 \times 10^{-2}$, respectively, confirming the conjectured one-dimensional magnetic behavior at high temperatures.

\section{SPECIFIC HEAT}

Recently ${ }^{15,16}$ the magnetic heat capacity of linear $S=1$ systems described by Eq. (1) has been calculated numerically, which-in principle-enables us to analyze the specific-heat data in more detail. Moreover, a reliable separation of the magnetic and lattice contribution to the heat capacity in TMNC seems possible, since the lattice heat capacity of the isomorphic TMCC and TMMC has been determined fairly accurately. ${ }^{8}$ The magnetic contribution $C_{M}$ was obtained by subtracting the scaled heat capacity of TMCC. The scaling factor, which was assumed to be temperature independent in the region under consideration, was determined by the conditions $C_{M}>0$ and $\partial C_{M} / \partial T<0$ for $T>20$ $K$. This resulted in a scaling factor $1.230 \pm 0.005$. The total evaluated magnetic entropy increase, including the extrapolated contribution $0.02 R$ below $T=0.64 \mathrm{~K}$, did amount to $1.09 R$, which corresponds 


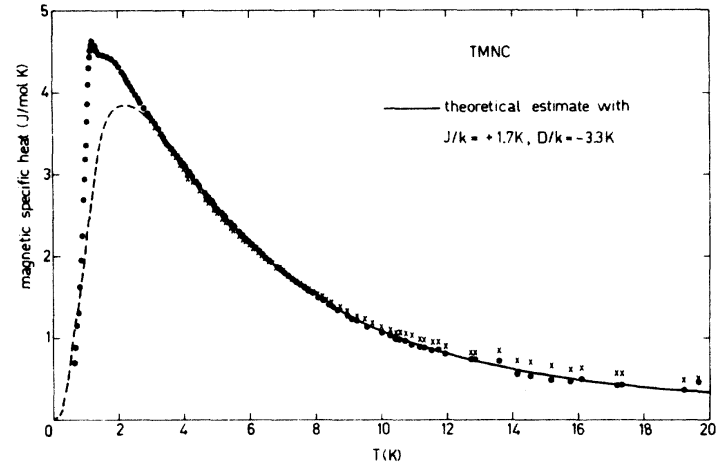

FIG. 1. Experimental magnetic heat capacity of TMNC. The circles are the data obtained by subtracting the scaled heat capacity of TMCC. The crosses represent the data obtained by subtracting the scaled lattice heat capacity of TMMC. The drawn curve denotes the best fit with $J / k=1.7 \mathrm{~K}, D / k=-3.3 \mathrm{~K}$. The dashed part of the curve indicates the estimated low-temperature behavior of the magnetic specific heat (Refs. 15 and 16).

within $1 \%$ to the theoretical value $R \ln 3$.

Since the mass difference between the $\mathrm{Ni}^{++}$and the $\mathrm{Cd}^{++}$ion is rather large, use of a temperatureindependent scaling factor may produce some systematic deviations. In order to check the accuracy of the procedure outlined above we determined $C_{M}$ in a similar way using the inferred lattice contribution of TMMC, ${ }^{8}$ which resulted in a scaling factor $1.125 \pm 0.005$. The results of both scaling procedures are plotted in Fig. 1. Both sets of data are quite consistent; significant differences are found for $T>12 \mathrm{~K}$ only. The data for $3.5<T<20 \mathrm{~K}$ could be described within the experimental uncertainty with the Hamiltonian (1) with $J / k=+1.7$ $\pm 0.3 \mathrm{~K}$, and $D / k=-3.3 \pm 0.5 \mathrm{~K}$. The parameters were obtained by a least-squares fit to the experimental $C_{M}$ data. The best fit is shown as a drawn curve in Fig. 1. Below $T \simeq 3 \mathrm{~K}$ the observed magnetic specific heat rises systematically above the theoretical prediction, indicating that interchain interactions in this compound are presumably no longer negligible. This is supported by the fact that the three-dimensional ordering temperature is comparable to the temperature corresponding to the maximum of $C_{M}$ predicted for a linear chain model.

\section{DISCUSSION}

The values for $J$ and $D$ obtained from different experimental techniques are listed in Table I. It appears that the present values are somewhat higher than those reported by Dupas et al. ${ }^{13}$ which is most likely explained by the fact that their interpretation is based upon a Curie-Weiss behavior of the susceptibility at liquid-hydrogen temperatures. This is inconsistent with earlier measurements of Gerstein et al., ${ }^{9}$ which reveal a CurieWeiss behavior at temperatures above $T=30 \mathrm{~K}$ only. In general, a $1 / \chi$ vs $T$ plot at temperatures low compared to the region in which the CurieWeiss law $\chi=C /(T-\theta)$ strictly holds will yield an extrapolated intersection $\Theta^{*}$ on the temperature axis with $\theta^{*}<\theta$. This indicates that the parameter values obtained from the single crystal susceptibility measurements are too low indeed.

The intrachain interaction in TMNC is found to be ferromagnetic, whereas this interaction in the isomorphic TMMC is strongly antiferromagnetic. As each magnetic ion is linked with its nearest neighbors within the chain by three chlorine bridges with a bond angle of about $80^{\circ}$, this behavior is not inconsistent with the model of Anderson, ${ }^{17}$ which predicts, for a $90^{\circ}$ bridge, a decreasing importance of the antiferromagnetic contributions to the superexchange going from $3 d^{5}$ to $3 d^{8}$.

\section{ACKNOWLEDGMENTS}

The continuous interest and discussions with Professor P. van der Leeden and Dr. C. H. W. Swüste are gratefully acknowledged.

TABLE I. Magnitude of the intrachain exchange interaction and the single-ion anisotropy in TMNC obtained from different experimental techniques.

\begin{tabular}{clllr}
\hline \hline Technique & $J / k(\mathrm{~K})$ & $D / k(\mathrm{~K})$ & \multicolumn{2}{c}{ Comment } \\
\hline Powder & $+1.8 \pm 2.0$ & $\ldots$ & Ref. 9: $\Theta$ value & $30-80 \mathrm{~K}$ \\
susceptibility & +1.9 & $\ldots$ & Ref. 9: Ising $S=1$ & $3-80 \mathrm{~K}$ \\
& +1.0 & $\ldots$ & Ref. 9: Fisher $S=1$ & $2-80 \mathrm{~K}$ \\
Specific heat & -2.73 & $\ldots$ & Ref. 10 & $6-20 \mathrm{~K}$ \\
Single-crystal & $+1.1 \pm 0.1$ & $-2.1 \pm 0.5$ & Ref. 13 & $13-20 \mathrm{~K}$ \\
susceptibility & & & & \\
Specific heat & $+1.7 \pm 0.3$ & $-3.3 \pm 0.5$ & Present work & $3.5-20 \mathrm{~K}$ \\
\hline \hline
\end{tabular}


${ }^{1}$ G. D. Stucky, Acta Crystallogr. B 24, 330 (1968).

${ }^{2}$ P. S. Peercy, B. Morosin, and G. A. Samara, Phys. Rev. B 8, 3378 (1973).

${ }^{3}$ L. R. Walker, R. E. Dietz, K. Andres, and S. Darak, Solid State Commun. 11, 593 (1972).

${ }^{4}$ R. J. Birgeneau, R. Dingle, M. T. Hutchings, G. Shirane, and S. L. Holt, Phys. Rev. Lett. 26, 718 (1971).

${ }^{5}$ M. T. Hutchings, G. Shirane, R. J. Birgeneau, and S. L. Holt, Phys. Rev. B $\underline{5}, 1999$ (1972).

${ }^{6}$ R. Dingle, M. E. Lines, and S. L. Holt, Phys. Rev. 187, 643 (1969).

${ }^{7} \mathrm{~K}$. Takeda, Phys. Lett. A 47, 335 (1974).

${ }^{8}$ W. J. M. de Jonge, C. H. W. Swüste, K. Kopinga, and K. Takeda, Phys. Rev. B 12, 5858 (1975).

${ }^{9}$ B. C. Gerstein, F. D. Gehring, and R. D. Willett, J. Appl. Phys. 43, 1932 (1972).
${ }^{10}$ M. Hurley and B. C. Gerstein, J. Chem. Phys. 59, 6667 (1973).

${ }^{11}$ C. Domb and A. R. Miedema, Progress in Low Temperature Physics (North-Holland, Amsterdam, 1964), Vol. IV.

${ }^{12} \mathrm{C}$. Weng, Ph.D. thesis (Carnegie-Mellon University, 1968) (unpublished).

${ }^{13}$ C. Dupas and J. P. Renard, J. Chem. Phys. $\underline{61}, 3871$ (1974).

${ }^{14}$ T. Oguchi, Phys. Rev. 133, A1098 (1964).

${ }^{15} \mathrm{~T}$. de Neef and W. J. M. de Jonge, Phys. Rev. B 11, 4402 (1975).

${ }^{16}$ H. W. J. Blöte, Physica 79, 427 (1975).

${ }^{17}$ P. W. Anderson, Solid State Physics (Academic, New York, 1963), Vol. 14. 